\title{
Delegation of Contracting in the Private Provision of Public Services*
}

\author{
John Bennett ${ }^{\dagger}$ and Elisabetta Iossa ${ }^{\ddagger}$
}

April 2005

\begin{abstract}
We use an incomplete-contract approach to compare contracting out by a public sector agency with the delegation of contracting out to a public-private partnership (PPP) that is a joint venture between private and sector agents. The PPP maximizes a linear combination of profit and social benefit. Such delegation may be desirable to curb innovations that reduce the cost of provision but also reduce social benefit. Delegation may be undesirable for innovations that increase social benefit but also raise costs. Our results are explained in terms of the shadow cost of public funds and the negotiating stance of the PPP.
\end{abstract}

Keywords: Delegation, Private Finance Initiative, Public Private Partnership, Public Service Provision.

JEL Classification: H11, L33.

\section{Introduction}

In the last couple of decades the contracting out of public service provision to the private sector has become increasingly popular in many countries, and a variety of administrative arrangements have been used (see Grout and Stevens, 2003). In the UK, for example, under the Private Finance Initiative (PFI), a government agency specifies broadly the public service required, and contracts with a private sector provider (typically a consortium), which is then free to supply the service in the manner it chooses (HM Treasury, 1998). Indeed PFI

\footnotetext{
${ }^{*}$ Financial support from the ESRC under grant R/000/22/3811 is gratefully acknowledged. We wish to thank Gabriella Legrenzi and Zoe Moss for valuable discussions.

${ }^{\dagger}$ Brunel Business School, Brunel University, Uxbridge, Middlesex, UB8 3PH, UK.

${ }^{\ddagger}$ Brunel Business School, Brunel University, Uxbridge, Middlesex, UB8 3PH, UK; and C.M.P.O., University of Bristol.
} 
itself can be organized in many different ways. The classic form is DBFO, where design, building, financing and operation of the relevant facility are all undertaken by the service provider; but in some circumstances less extensive involvement by the provider can be preferable (IPPR, 2001; Bennett and Iossa, 2004). Arrangements similar to PFI have been used in other developed economies (Rosenau, 2000) and in developing economies (Harris, 2003).

A recent innovation in the UK has been for government agencies to join with private consortia to form public-private partnerships (PPPs) that will manage the long-term provision of a specified type of public service in a given area, performing the strategic role of identifying needs and co-ordinating investments. For example, this has happened in the health sector, where PPPs known as Local Improvement Finance Trusts, have been established. These are joint ventures between the private sector, the National Health Service, and local government authorities (Department of Health/Partnerships UK, 2001). Similar schemes - Local Education Partnerships - are currently proposed for secondary education (Partnerships for Schools, 2004). The private sector is the dominant partner, but the presence of public sector agencies ensures that private profit is not the sole objective. Various contractual arrangements are available for operating these joint ventures. For example, the private sector members of the PPP may themselves be awarded the contract, which may be in the form of PFI, or of more traditional procurement (whereby the public sector finances and designs the project itself, leaving the contractor merely to build the facility). Alternatively, there may be contracting out to a third-party service provider, using PFI or traditional procurement.

In this paper we focus on PFI, and study the rationale for delegating contracting with the service provider to a PPP. We assume throughout that the provider has residual rights of control over the way the service is provided, as under PFI. We suppose that, after the initial contract has been agreed, the provider may come up with innovative ways of providing the service. Since such innovations could not be foreseen when the initial contract was drawn up, bargaining may take place over the splitting of the surplus from implementation of the innovations. The service provider's anticipation of the outcome of such bargaining affects 
its incentive to research possible innovations. However, having control rights, it may instead choose to implement an innovation unilaterally.

We compare two scenarios. The first is 'centralized contracting,' whereby a public sector agency (for example, a central government Ministry) contracts with the service provider. Examples in the UK include fighter-pilot training, which has been contracted out to the private sector by the Ministry of Defence, and the development of a new computerized system for the Passport Office. The second is 'delegated contracting,' whereby the public sector delegates to a PPP the task of contracting with the service provider. ${ }^{1}$ The critical difference between these two cases lies in the objective functions of the public sector agency and the PPP. The public sector agency is assumed to be welfare-maximizing, disliking monetary transfers to firms insofar as the transfers create the need to raise funds through distortive taxation. In contrast, the PPP maximizes a function that is a combination of its own profit and the social benefit from the public service, having some concern for social benefit because representatives of the service users have seats on the board of the PPP. Thus, in considering the PPP case, we are examining the effects of delegation of contracting to an agent that does not maximize social welfare, though has some concern for social benefit.

Delegation to a PPP works as a commitment for the public sector to take a tougher approach towards the service provider. We show that if taxation is not very distortive and therefore transfers to the firm have little weight in the welfare function, delegation will give the provider better incentives to invest in cost-reducing activities that have an adverse impact on quality. However, since delegation to a tougher negotiator worsens the hold-up problem that arises because of the unverifiability of an investment in quality enhancement, there results a worsening of its incentives to undertake benefit-enhancing investment that reduce profits. These results suggest that delegation to a PPP may create a trade off: it improves incentives for one type of investment and worsens incentives for the other. It also follows that delegation is more likely to be optimal when investment in cost-reducing activities that may

\footnotetext{
${ }^{1}$ A potential problem with such an arrangement that is beyond the scope of this paper, but which is noted by Partnerships for Schools (2004), is the overlap of personnel belonging to the PPP and service provider.
} 
have an adverse impact on social benefit is unverifiable, when investment in benefit-enhancing activities is verifiable, and when the shadow cost of public funds is low.

An alternative interpretation of our model is that whereas the public sector agency is at the central government level, the 'PPP' is actually a local government. Our analysis thus compares PFI contracting by a central government agency with PFI contracting by a local government. The objective function of the 'PPP' must then be reinterpreted, for a local government would not be concerned with profit as such. Its objective function would include both the social benefit from the public service under consideration and the social benefit from other public services that are not in our model. But the ability to provide the latter public services can be proxied by the financial position of the local government; that is, 'profit' in its objective function can be regarded as a composite of other public services.

In the theoretical literature, the potential advantage, via commitment, of delegation of a task to an agent, whose objective differs from that of the principal, is well-known and has been analyzed deeply (see Drazen, 2000, for an overview). There is also a smaller literature that relates to the delegation of bargaining and is relevant to the issue of public service provision. The potential advantage of delegating bargaining was first noted by Schelling $(1956,1960)$, and the recent literature on this topic was initiated by Fershtman, Judd and Kalai (1991). If a principal delegates bargaining responsibility to an agent whose incentives differ from those of the principal, this will affect the outcome of bargaining with a third party. The principal can benefit from this arrangement if its own contract with the agent offers appropriate incentives and is not too costly. To obtain this result, Fershtman et al. assume that the principal is able to commit to this contract. The commitment assumption is potentially a weak point in this argument: without it, the agent's role may be superfluous. However, Bester and Sákovits (2001) formulate a variation on the Rubinstein alternating-offers bargaining model in which the agent may interrupt negotiation with the third party in order to renegotiate terms with the principal. They show that delegation can then still be advantageous to the principal.

In the Bester-Sákovits model there is still some commitment effect because renegotiation 
takes time, and so is assumed costly. Another way of achieving commitment is through repetition. A principal would be willing to bear the costs of refusing to renegotiate on one contract because of the effect on the expectations of the agent and the third party in future contracts. In the institutional set-ups that we consider in this paper, the PPP to which the government agency delegates contracting is set up to deal with all the projects within its sphere of operation over an extended period of time. Reputation would therefore be a major concern for the agency. In our analysis we make the simplifying assumption that the government is able to commit not to renegotiate its contract with the PPP. The alternatives of building directly on the Bester-Sákovits framework or of modeling repetition directly would be more complicated and would yield less sharp results.

Several recent papers use the incomplete-contract approach to analyze alternative forms of public service provision. Hart, Shleifer and Vishny (1997) compare contracting out with in-house provision to a single private firm, while Schmitz (2000) examines the role of joint public-private ownership in this model. Besley and Ghatak (2001) study how the optimal provision of a public good depends on who values it most. Bös and De Fraja (2002), Hart (2003) and Bennett and Iossa (2004) examine various issues associated with bundling the building and management of an asset in the hands of a single agent. None of these papers considers the issue of delegation of contracting.

In Section 2 the model is set up and the cases of centralized and decentralized contracting are considered, while in Section 3 we compare these cases. In these sections we assume that the PPP is simply given a fixed budget. In Section 4, however, we examine briefly the implications of this budget being endogenous, with parameters being chosen optimally. In Section 5, which concludes, we consider briefly the reinterpretation of the PPP as a local government. Proofs are given in an Appendix. 


\section{The Model}

We follow Hart, Shleifer and Vishny (1997), amongst others, in assuming that the agent that contracts out service provision is able to write a contract specifying a basic level of the service required from the service provider, but that there are other aspects of service provision that cannot be contracted upon ex ante. Thus, ownership of the project matters, for it provides control rights, that is, the right to make decisions in all circumstances not specified in the initial contract. We denote the public sector agency by $G$, the PPP by $P$ and the service provider by $S$. The task of contracting with $S$ may be undertaken by $G$ or by $P$. In either case $G$ or $P$, as appropriate, agrees to pay $S$ in return for service provision at a basic standard. Administrative costs are assumed the same in each setting, and we assume a zero cost of managing $S$. To simplify, we do not allow for discounting.

The social benefit $B$ and the $\operatorname{cost} C$ of service provision by $S$ are given by

$$
\begin{aligned}
& B(i, e)=B_{0}+\beta(i)-b(e), \\
& C(i, e)=C_{0}-c(e)+\gamma(i) .
\end{aligned}
$$

where $B_{0}$ and $C_{0}$ are positive constants; $\beta(0)=0, \beta^{\prime} \geq 0, \beta^{\prime}(0)=\infty, \beta^{\prime}(\infty)=0, \beta^{\prime \prime}<0$, $\beta^{\prime \prime \prime}=0 ; b(0)=0, b^{\prime} \geq 0, b^{\prime}(0)=0, b^{\prime}(\infty)=\infty, b^{\prime \prime} \geq 0, b^{\prime \prime \prime}=0 ; c(0)=0, c^{\prime}>0, c^{\prime}(0)=\infty$, $c^{\prime}(\infty)=0, c^{\prime \prime}<0, c^{\prime \prime \prime}=0 ; \gamma(0)=0, \gamma^{\prime} \geq 0, \gamma^{\prime}(0)=0, \gamma^{\prime}(\infty)=\infty, \gamma^{\prime \prime} \geq 0, \gamma^{\prime \prime \prime}=0 . \quad B_{0}$ and $C_{0}$ are the respective social benefit and cost of providing the basic service. $\{i, e\}$ are investments made by $S$ in innovative methods for service provision. If implemented, $i$ raises the quality of the service, but a side-effect is that cost is raised. Similarly, e reduces cost, but a side-effect is that there is some sacrifice in the quality of the service. We normalize the cost of one unit of $i$ or $e$ as unity; and, throughout, we speak of $e$ and $i$ interchangeably as 'innovations' and 'investments.'

We assume that any innovation $i$ or $e$ by the service provider $S$ can be implemented only by $S$, and that $S$ has control rights over the project, as under PFI. Neither $i$ nor $e$ can be specified ex ante, but ex post $S$ can contract with $P$ or $G$ (depending on who is in charge) 
over the implementation of such innovations. $S$ can implement an innovation unilaterally if it wishes. However, instead of implementing unilaterally, it may negotiate with $G$ or $P$ (depending on who is in charge) for a side-payment in return for implementation. We view unilateral adoption as the outside option for $S$. For $S$ to negotiate with $G$ or $P$ it must thereby obtain a higher payoff than by exercising its outside option.

The total (net) side-payment made between any two parties in the model potentially has two components. The first is the amount specified ex ante in the contract that is initially drawn up, that is, the payment that would obtain if service provision were to be at its basic level. The second is an amount that is paid later through negotiation for implementation of an innovation. We denote the total side-payment by party $k$ to party $l$ by $\bar{s}_{k l}$. We return to the components of this payment below.

$S$ 's objective function is profit $\Pi$, where

$$
\Pi=\bar{s}_{k S}-C-i-e ; \quad k=G, P,
$$

and where $\bar{s}_{k S}$ is the side-payment made by the party who negotiates with $S$, that is, by $G$ under regular centralized contracting and by $P$ under delegation.

$P$ 's utility is

$$
U_{P}=\bar{s}_{G P}-\bar{s}_{P S}+\alpha B, \quad 0 \leq \alpha<1 .
$$

$\bar{s}_{G P}$ is the side payment $P$ receives from $G ; \bar{s}_{P S}$ is the side payment made by $P$ to $S$; and $\alpha \in(0,1)$ is the weight that $P$ places on the social benefit from the project. The weight $\alpha$ may be assumed positive because of the presence of representatives of service users on the board of the PPP. We focus on the case in which $\bar{s}_{G P}$ is a fixed budget allocated to $P$ by $G$. With this budget constraint, the payment $P$ receives from $G$ must at least cover its payment to $S: \bar{s}_{G P} \geq \bar{s}_{P S}$.

$G$ 's objective function is social welfare $W$, which is the sum of consumer surplus and the profit of $S .^{2}$ Taxation is assumed distortive and we denote the shadow cost of public funds

\footnotetext{
${ }^{2}$ We can also interpret $W$ as the sum of consumer surplus, profit and the utility of $P$.
} 
by $\theta \in(0,1)$; that is, $\theta$ is the excess burden associated with a $\$ 1$ payment. Thus, we have

$$
W=B-C-\theta \bar{s}_{G P}-\theta \bar{s}_{G S}-i-e,
$$

where $\bar{s}_{G P}$ is set equal to zero if there is centralized contracting, and $\bar{s}_{G S}$ is set equal to zero if there is delegation.

To focus on the effect of delegation on the ex-post renegotiation between $S$, and $G$ or $P$, we assume that bargaining powers are distributed ex ante in such a way that (i) under centralized contracting, $G$ extracts the whole surplus from $S$; and (ii) under delegation, $P$ extracts the whole surplus from $S$, and $G$ in turn keeps $P$ on its budget constraint. Without these assumptions, the comparison of the effects of centralized contracting and delegation would be distorted by the fact that under delegation there would be three agents involved in bargaining ( $G$ bargains with $P$, and $P$ bargains with $S$ ), while under centralized contracting there would be only two agents $(G$ bargains with $S$ ). The share of any bargaining surplus then accruing to $G$ or $S$ would differ between the two cases, and the extent of the difference would depend on the bargaining weights assumed for pairwise negotiation. Our assumptions (i) and (ii) avoid this problem. Furthermore, a rationale for (i) would be that private firms compete to get the public sector contract, and the public sector exploits this situation when agreeing the contract with $S$, thereby gaining all of the surplus for itself. Assumption (ii) can be justified on similar grounds, with private firms competing to be the one chosen to join the PPP. Writing the investment levels of $i$ and $e$ actually chosen, for a given institutional arrangement, as $\hat{\imath}$ and $\hat{e}$, respectively, we have

$$
\begin{aligned}
& \bar{s}_{G S}=C(\hat{\imath}, \hat{e})+\hat{\imath}+\hat{e} \\
& \bar{s}_{G P}=\bar{s}_{P S} \\
& \bar{s}_{P S}=C(\hat{\imath}, \hat{e})+\hat{\imath}+\hat{e} .
\end{aligned}
$$

Components of the total side-payments that derive from ex post bargaining over implementation of innovations are endogenous. Nonetheless, given that each player has perfect foresight, and given our assumptions over bargaining powers, the total payments will be such 
that (6) is satisfied. Thus, through an appropriate choice of ex ante payments (that is, the payments agreed in the initial contract for the basic level of service provision), and given the levels of ex post payments, (6) holds. From now on we phrase our analysis in terms of the ex post payments, recognizing that the ex ante payments adjust such that (6) holds. We shall denote the ex post payment from $k$ to $l$ by $s_{k l}$.

Using (6), we can rewrite $W$, taking into account that only one of the side-payments $\bar{s}_{G S}$ and $\bar{s}_{P S}$ will be made, by

$$
W=B_{0}-(1+\theta)\left[C_{0}+c(e)-\gamma(i)+i+e\right]+\beta(i)-b(e) .
$$

Due to the excess burden of taxation, any increase in cost is weighted by $1+\theta$ because it has to be covered through distortive taxation; any cost reduction is weighted by $1+\theta$ because it reduces the need to raise funds through distortive taxation.

As a benchmark, it is useful to specify the first-best solution, which would obtain under either of these institutional arrangements if $i$ and $e$ were verifiable. Maximizing (7) with respect to $i$ and $e$ yields

$$
\begin{aligned}
\beta^{\prime}\left(i^{*}\right)-(1+\theta) \gamma^{\prime}\left(i^{*}\right) & =1+\theta, \\
-b^{\prime}\left(e^{*}\right)+(1+\theta) c^{\prime}\left(e^{*}\right) & =1+\theta .
\end{aligned}
$$

In the first-best world, investments are chosen to equate marginal social benefit to marginal social cost, appropriately weighted by $1+\theta$ because of the presence of distortive taxation. Because of (6), this applies whether $G$ contracts with $S$ directly, or instead delegates this task to $P$.

\subsection{Centralized Contracting}

In this case $G$ contracts with $S$, which sinks investments $i$ and $e$ in innovation. Then, for each innovation, $S$ either implements unilaterally or bargains with $G$ over implementation. In any bargaining that takes place, since $i$ and $e$ are sunk, $G$ maximizes $B-C-\theta s_{G S}$, rather than $W$. Since $S$ is now entrenched as the provider, its bargaining power is not eroded by 
competition from other potential providers (given that it provides the service at, at least, the basic level specified in the initial contract). We therefore assume that $S$ and $G$ have equal bargaining powers.

Implementation of innovation $i$ reduces $S$ 's profit, and so $S$ will not be willing to implement unilaterally. However, implementation raises $B-C$, and so $G$ will be willing to make a side payment to induce implementation. With Nash bargaining over the size of the side-payment, $G$ pays $S$ an amount $s_{G S}=\arg \max _{z}[\beta(i)-\gamma(i)-\theta z][z-\gamma(i)]$. Thus,

$$
s_{G S}=\frac{1}{2 \theta}[\beta(i)-(1-\theta) \gamma(i)]
$$

Substituting for $s_{G S}$ in (3), we find that, at the time of choosing $i, S$ sets $i=i_{G}$ to maximize $\Pi$, where $i_{G}$ solves:

$$
\frac{1}{2 \theta}\left[\beta^{\prime}\left(i_{G}\right)-(1+\theta) \gamma^{\prime}\left(i_{G}\right)\right]=1
$$

Lemma 1 Under centralized contracting there is overinvestment in quality innovation: $i_{G}>$ $i^{*}$. The level of overinvestment decreases with the shadow cost of public funds, $d i_{G} / d \theta<0$.

Lemma 1 results from the existence of a shadow cost of public funds, transfers from $G$ to $S$ being costly to $G$ because they require funding by distortive taxation. Overinvestment arises because investment $i$ is already sunk at the time of renegotiation, so that its full social cost $1+\theta$ is not taken into account. However, the higher is the shadow cost of public funds $\theta$, the smaller is the willingness of $G$ to compensate $S$ for its investment. Foreseeing this, $e x$ ante, $S$ (over)invests less. ${ }^{3}$ Note that Lemma 1 contrasts strongly with that of Hart, Shleifer and Vishny (1997), who exclude considerations of distortive taxation and find that there is always underinvestment in quality innovations.

Now consider innovation $e$, and denote the level of $e$ chosen under centralized contracting by $e_{G}$. Since implementation of $e$ would reduce $S$ 's costs by $c(e), S$ may choose to assert its control rights to implement $e$ without consulting $G$. Anticipating that it will choose to

\footnotetext{
${ }^{3}$ If $\theta$ were sufficiently large $(\theta \rightarrow 1)$, the correspondingly strong aversion by $G$ to paying $S$ would result in $S$ holding back investment to the first-best level $i^{*}(\theta)$.
} 
implement unilaterally, maximization of ex ante profit $\Pi$ by $S$ would then imply that it sets $e_{G}=\tilde{e}_{G}$ to satisfy

$$
c^{\prime}\left(\tilde{e}_{G}\right)=1
$$

However, $G$ may also benefit from the implementation of $e$. Consequently, instead of implementing without negotiation (the outside option), $S$ may bargain with $G$ to get a sidepayment $s_{G S}$ for implementation. Then $s_{G S}=\arg \max _{z}[-b(e)+c(e)-\theta z][z+c(e)]$, so that, for given $e$,

$$
s_{G S}=\frac{1}{2 \theta}[-b(e)+(1-\theta) c(e)] .
$$

In this case $S$ would maximize ex ante profit $\Pi$ taking this side-payment into account. Thus it would set $e_{G}=\hat{e}_{G}$, where

$$
\frac{1}{2 \theta}\left[-b^{\prime}\left(\hat{e}_{G}\right)+(1+\theta) c^{\prime}\left(\hat{e}_{G}\right)\right]=1 .
$$

The proposition below characterizes the relationship between $\tilde{e}_{G}$ and $\hat{e}_{G}$ and the conditions under which either obtains.

Lemma 2 Under centralized contracting there is overinvestment in cost reducing activities: $\tilde{e}_{G}, \hat{e}_{G}>e^{*}$. Three cases may arise: (i) $e_{G}=\hat{e}_{G}>\tilde{e}_{G}$ (ii) $e_{G}=\hat{e}_{G}<\tilde{e}_{G}$; (iii) $e_{G}=\tilde{e}_{G}>\hat{e}_{G}$. Case (i) is more likely to occur when $\theta$ is low. Case (ii) is more likely to occur at an intermediate level of $\theta$. Case (iii) is more likely to occur when $\theta$ is high.

Since $S$ has control rights, it can implement the innovation unilaterally without bargaining with $G$. If this occurs, there is overinvestment because $S$ does not take into account the negative effect that innovation has on social benefit. This explains why $\tilde{e}_{G}>e^{*}$. However, $S$ may also negotiate with $G$, in which case, since the social cost of $e$ is sunk, it is not taken into account in the negotiation, and the negative effect of $e$ on social benefit is taken into account only partially. This explains why $\hat{e}_{G}>e^{*}$.

In this setting there are three possibilities, depending on the shadow cost of public funds $\theta$. The innovation $e_{G}$ generates a cost reduction that is valuable to both $S$ and $G$ (though 
it also has an adverse effect on social benefit). Provided $\theta$ is sufficiently low, $G$ is willing to compensate $S$ for its investment, and so bargaining between $S$ and $G$ occurs, as shown in cases (i) and (ii) of the proposition, where $e_{G}=\hat{e}_{G}$. As $\theta$ rises, $G$ is not willing to compensate $S$ so much, and so, foreseeing this, $S$ does not set $\hat{e}_{G}$ so high. Thus, in case (i), where $\theta$ is at a relatively low level, $\hat{e}_{G}$ exceeds the level $\tilde{e}_{G}$ that would obtain if $S$ implemented unilaterally; but in case (ii), where $\theta$ takes an intermediate value, $\hat{e}_{G}$ is less than $\tilde{e}_{G}$. Finally, for high enough values of $\theta$ a transfer to $S$ becomes so costly for $G$ that bargaining would then involve a payment in the opposite direction, from $S$ to $G$. $S$ therefore refuses to bargain, implementing the innovation unilaterally. This is case (iii) in the proposition, where $e_{G}=\tilde{e}_{G}>\hat{e}_{G}$.

\subsection{Delegated Contracting}

Suppose now that the task of contracting with $S$ is delegated to $P$, and consider first the innovation $i$ in quality improvement. If this were implemented without a side-payment, $P$ would gain $\alpha \beta(i)>0$, while $S$ would lose $\gamma(i)$. Hence, $P$ will wish implementation to occur, while $S$ will only be willing to implement in return for an appropriate side payment $s_{P S}$. With Nash bargaining, $s_{P S}=\arg \max _{z}[\alpha \beta(i)-z][z-\gamma(i)]$, that is,

$$
s_{P S}=\frac{1}{2}[\alpha \beta(i)+\gamma(i)] .
$$

Recognizing that this side-payment will be made, $S$ sets $i=i_{P}$ to maximize $-\gamma(i)+s_{P S}-i$, and so $i_{P}$ is given by

$$
\frac{1}{2}\left[\alpha \beta^{\prime}\left(i_{P}\right)-\gamma^{\prime}\left(i_{P}\right)\right]=1
$$

Lemma 3 Under delegated contracting a sufficient condition for there to be underinvestment in quality-enhancing innovations $\left(i_{P}<i^{*}\right)$ is that $\alpha \leq 1 /(1+\theta)$. The level of investment $i_{P}$ increases with $\alpha$.

The reason why underinvestment may result under delegated contracting is twofold. First, $P$ values social benefit less than $G$ does. Second, $P$ dislikes making payments to $S$ (and in particular it dislikes making payments more than $G$ does). However, the more $P$ cares about 
social benefit (the greater is $\alpha$ ) the more it will be willing to pay $S$ to implement any given innovation. Foreseeing this, $S$ invests more when $\alpha$ is greater. If, however, $\alpha \leq 1 /(1+\theta)$, there is sure to be underinvestment. In the context of delegation to PPPs in the UK, as discussed in the introduction, the private participant is the dominant partner, so we expect that $\alpha<1 / 2$, which would ensure that $\alpha \leq 1 /(1+\theta)$.

With regard to innovation $e$, since $S$ has control rights it can exercise its outside option and implement without negotiation. In that case it sets $e=e_{P}$ to maximize $\Pi$ without side-payments, where

$$
c^{\prime}\left(e_{P}\right)=1
$$

If, alternatively, $S$ were to bargain with $P$, the side-payment would be given by $\arg \max _{z}[-\alpha b(e)-$ $z][z+c(e)]$; that is, the side-payment to $S$ would be negative. Therefore, with delegated contracting $S$ always prefers to implement the innovation unilaterally and $e$ is given by (15).

Lemma 4 Under delegated contracting, there is overinvestment in cost reducing activities: $e_{P}>e^{*}$.

Overinvestment results because $S$ does not take into account the effect of its innovation on social benefit.

\section{Comparisons}

We now compare the levels of investments $i$ and $e$ under the two regimes, and then consider the implications for social welfare.

Proposition 1 (i) A sufficient condition for delegated contracting to result in less qualityenhancing investment than centralized contracting does $\left(i_{G}>i_{P}\right)$ is that $\alpha \leq 1 /(1+\theta)$. (ii) If the shadow cost of public funds is low, delegated contracting results in less cost-reducing investment than centralized contracting does: $e_{P}<e_{G}$. When the shadow cost of public funds is higher, delegated contracting results in at least the same level of cost-reducing investment as centralized contracting does: $e_{P} \geq e_{G}$. 
The intuition for Proposition 1(i) follows from the fact that under centralized contracting there is overinvestment, while, if $\alpha \leq 1 /(1+\theta)$, delegated contracting leads to underinvestment, for reasons explained in the previous section. Proposition 1(ii) stems from the fact that, under both centralized and delegated contracting, $S$ has control rights and can implement the innovation unilaterally, choosing the (same) profit-maximizing level of $e$. However, $S$ also has the option of negotiating over implementation. Whilst under delegated contracting this option is never profitable for $S$, under centralized contracting it can be profitable. In this case $S$ manages to extract a contribution from $G$ which will boost or depress its investment, depending on whether the level of the shadow cost is low or high.

The next proposition derives the implications of Proposition 1 for social welfare.

Proposition 2 If $\alpha \leq 1 /(1+\theta)$, delegation of contracting is never optimal for qualityenhancing innovations. Delegation of contracting is optimal for cost-reducing innovations only if the shadow cost of public funds is low.

Given that $\alpha \leq 1 /(1+\theta)$, delegation cannot be optimal for benefit-enhancing investment $i$. As shown in the proof of this proposition, this is because the overinvestment problem under centralized contracting is never as severe, in welfare terms, as the underinvestment problem under delegation. Delegation of contracting is strictly optimal for cost-reducing investment $e$ only if it yields a lower level of overinvestment. This occurs when, under centralized contracting, we are in case (i) of Lemma 2, which is more likely to occur if the shadow cost of public funds is low. It also follows that delegation is more likely to be optimal when investment in cost-reducing activities that may have an adverse impact on social benefit is unverifiable, whilst investment in benefit-enhancing activities is verifiable, and the shadow cost of public funds is low.

\section{A Variable Budget for $P$}

We have assumed that $G$ gives $P$ a fixed budget. Suppose, however, that $G$ reimburses $P$ ex post for a proportion $1-\mu \in(0,1)$ of its expenses $s_{P S}$; that is, the fraction $\mu$ of $s_{P S}$ is borne 
by $P$. We rule out $\mu$ being as low as 0 because then $P$ would be willing to pay any amount to $S$, and, although this would enable a first-best solution to be achieved, there would be considerable scope for corruption (and the same argument holds a fortiori for $\mu<0$ ). The case of $\mu=1$ has, in effect, already been covered. ${ }^{4}$

Intuitively, with a variable budget for $P$, delegation may be more likely to be optimal with respect to $i$ because, at the time of bargaining with $S, P$ would put a weight of less than one on the payment $s_{P S}$. It would thus would be more willing to reimburse $S$ for its sunk investment, leading to an increase in $i_{p}$. However, the possibility of making ex post payments would have no effect on the desirability of delegation for $e$ because bargaining on the implementation of $e$ does not take place under delegation for any $\mu \in(0,1)$. The following lemma summarizes the solution for a variable-budget case.

Lemma 5 With a variable budget for $P$, delegation of contracting will result in the first-best level of benefit-enhancing investment, $i=i^{*}$, if $\mu=\alpha \beta^{\prime}\left(i_{P}\right)(1+\theta) /\left[\beta^{\prime}\left(i_{P}\right)+3(1+\theta)\right] \equiv \bar{\mu}$ and $\bar{\mu}<1$. A sufficient condition for $\bar{\mu}<1$ is that $\alpha \leq 1 /(1+\theta)$. The variable budget has no effect on cost-reducing innovation e.

If $\bar{\mu}$, as defined in the lemma, is less than unity, the first-best level of investment $i$ is achieved by setting the budget share $\mu$ equal to $\bar{\mu}$. The inequality $\bar{\mu}<1$ is sure to be satisfied if $\alpha \leq 1 /(1+\theta)$ holds. In considering whether delegation is optimal, we must also take into account the effect on cost-reducing investment $e$. As specified in Proposition 2, this requires the shadow cost of public funds $\theta$ to be sufficiently low.

\section{Concluding Comments}

Developments in the practice of public service provision have recently run ahead of academic analysis. Delegation to a PPP of the task of contracting with service providers is an example of this. We have therefore begun to fill the gap in the literature in this paper by comparing

\footnotetext{
${ }^{4}$ We also rule out the remaining case, $\mu>1$, on the grounds of impracticality. $P$ would have an incentive not to report its marginal expenditures, so that, de facto, $\mu$ would be reduced to unity.
} 
contracting out by a public sector with the delegation of contracting out to a PPP that is a joint venture between the private sector (the dominant partner) and a public sector agent. The presence of the public sector agent ensures that some weight is place on social benefit in decision making.

Our main analysis is for the case in which the PPP is allocated a fixed budget. We show that delegation to a tougher agent may be desirable to curb innovations that reduce the cost of provision but have the side-effect of cutting social benefit. The critical factor underlying this result is that delegation to a tougher agent is desirable when incomplete contracts and the shadow cost of public funds could result in the service provider overinvesting. We also show, however, that, under a relatively mild constraint on parameter values, delegation is undesirable for innovations that increase social benefit, but have the side-effect of raising costs. Thus, in situations in which potential innovations are likely to be in cost-reducing, delegation of contracting can be a socially beneficial policy. We explain this result in terms of the negotiating stance of the PPP, which follows from its assumed objective: compared to the public sector agency it has a greater profit orientation and a smaller concern for social benefit. This parallels results on delegation in other areas of economics, for example in the delegation of the control of the money supply to a relatively conservative central banker.

We have ruled out in the paper the possibility that the PPP cares about the service provider's profit, say because it is represented on the provider's board. If, the PPP did so care, the underinvestment problem related to benefit-enhancing innovation would be reduced, since the PPP would be more willing to compensate the provider for an innovation. However, if the PPP were also willing to compensate the provider for implementation of a cost-reducing innovation there would be further overinvestment in this type of activity.

Our analysis suggests that, with delegation, the weight placed by the PPP on social benefits is a critical factor to the success of the scheme. This indicates that, in designing the new institutional arrangements, the proportion of users on the board of directors of the PPP should be a matter of particular concern. Indeed, if the value of $\alpha$ could be controlled precisely, 
delegation would result in a first-best level of investment in benefit-enhancing innovations.

If we reinterpret delegation as contracting by a local government, rather than a central one, there is no reason to assume that $\alpha<1$. Since we may suppose that the local government values the public service that features in our model equally to the other public services it provides, we may, for example, assume that $\alpha=1$. Our conclusions with respect to investment in cost-reducing innovations would be unaffected, but, other things being equal, the investment in benefit-enhancing innovations would be greater than when there is delegation to a PPP. Although our analysis would still apply, the inequality $\alpha \leq 1 /(1+\theta)$ could not be satisfied, and our results would become less clear-cut.

\section{Appendix}

In what follows, subscripts denote partial derivatives.

Proof of Lemma 1 From $(7), W_{i}(i)=\beta^{\prime}(i)-(1+\theta)\left(\gamma^{\prime}(i)-1\right)$. From (8), $W_{i}\left(i^{*}\right)=0$, whilst, using (10),

$$
W_{i}\left(i_{G}\right)=-(1-\theta)
$$

which is negative for all $\theta<1$. Since $W_{i}(i)$ is decreasing in $i$, it follows that $i_{G}>i^{*}(\theta)$ for $\theta<1$. Differentiation of $(10)$ gives $\partial i_{G} / \partial \theta<0$.

Proof of Lemma 2 From $(7), W_{e}(e)=-b^{\prime}(e)+(1+\theta)\left(c^{\prime}(e)-1\right)$. From $(9), W_{e}\left(e^{*}\right)=0$, whilst, using $(11), W_{e}(\tilde{e})=-b(\tilde{e})<0$. Since $W_{e}(e)$ is decreasing in $e$, it follows that $\tilde{e}>e^{*}$. Similarly, using (13), $W_{e}\left(\hat{e}_{G}\right)=-(1-\theta)$, and therefore $\hat{e}_{G}>e^{*}$ for $\theta<1$.

To derive the three cases specified in the lemma, let $Z(e) \equiv-b(e)+(1-\theta) c(e)$ and $\bar{e}_{0} \equiv \arg \max Z(e)$. Since $Z(0)=\infty$ and $Z(e)$ is concave, a positive level of $e$, which we denote by $e_{0}$, exists such that $Z\left(e_{0}\right)=0$. Then for $e<e_{0}$, we have $Z\left(e_{0}\right)>0$, whilst for $e>e_{0}$, we have $Z\left(e_{0}\right)<0$, where, from $(12), Z(e) \gtreqless 0$ implies $s\left(e_{G S}\right) \gtreqless 0$. Thus, for all $e<e_{0}$, the outside option does not bind and $Z^{\prime}(e)>0$, whilst for $e>e_{0}$ the outside option binds and $Z^{\prime}(e)<0$. 
Note that a necessary condition for $e_{G}=\tilde{e}_{G}$ to be an equilibrium strategy is that $Z\left(\tilde{e}_{G}\right) \leq$ 0 . This is because, if $Z\left(\tilde{e}_{G}\right)>0$, then, once $e_{G}=\tilde{e}_{G}$ is chosen, $S$ would do better by negotiating with $G$, rather than implementing the innovation unilaterally; and this would imply that, ex ante, $S$ would not want to choose $\tilde{e}_{G}$. Similarly, a necessary condition for $\hat{e}_{G}$ to be an equilibrium strategy is that $Z\left(\hat{e}_{G}\right) \geq 0$. This is because if $Z\left(\hat{e}_{G}\right)<0$, then, once $\hat{e}_{G}$ is chosen, $S$ would do better by implementing the innovation unilaterally, rather than negotiating with $G$; and this would imply that, ex ante, $S$ would not want to choose $\hat{e}_{G}$.

Define $H(e)=c^{\prime}(e)-1+Z^{\prime}(e) / 2 \theta$. It follows from (13) that $H\left(\hat{e}_{G}\right)=0$. Since $Z^{\prime}\left(\bar{e}_{0}\right)=0$, it also follows that $H\left(\bar{e}_{0}\right)>0$ if $c^{\prime}\left(\bar{e}_{0}\right)-1>0$, which, since $H^{\prime}(e)<0$, implies that $\bar{e}_{0}<(>)$ $\hat{e}_{G}$ as $c^{\prime}\left(\bar{e}_{0}\right)-1>(<) 0$.

Consider the case in which $c^{\prime}\left(\bar{e}_{0}\right)-1<0$, so that $\bar{e}_{0}>\hat{e}_{G}$ and thus $Z^{\prime}\left(\hat{e}_{G}\right)>0$. Since $H\left(\hat{e}_{G}\right)=0$, we have that $c^{\prime}\left(\hat{e}_{G}\right)-1<0$; and, since $c^{\prime}(\tilde{e})-1=0$ (from 13) and $c^{\prime \prime}<0$, we have $\hat{e}_{G}>\widetilde{e}$. Since $\bar{e}_{0}>\hat{e}_{G}$ and $e_{0}>\bar{e}_{0}$, we have $e_{0}>\hat{e}_{G}$ and therefore $Z\left(\hat{e}_{G}\right)>0$.

Let $c^{\prime}\left(\bar{e}_{0}\right)-1>0$, so that $\bar{e}_{0}<\hat{e}_{G}$ and thus $Z^{\prime}\left(\hat{e}_{G}\right)<0$. It follows from (13) that $c^{\prime}\left(\hat{e}_{G}\right)-1>0$, and, since, (from 11), $c^{\prime}(\tilde{e})-1=0$ and $c^{\prime \prime}<0$, we have $\hat{e}_{G}<\tilde{e}$. Since $\bar{e}_{0}<\hat{e}_{G}$ and $e_{0}>\bar{e}_{0}$, we have $e_{0} \gtreqless \hat{e}_{G}$ and therefore $Z\left(\hat{e}_{G}\right) \gtreqless 0$. It follows that if $Z\left(\hat{e}_{G}\right)>0$, then $\hat{e}_{G}$ is the solution, while if $Z\left(\hat{e}_{G}\right)<0$, the solution is $\tilde{e}$, where $Z\left(\widetilde{e}_{G}\right)<0$ is ensured by $Z\left(\hat{e}_{G}\right)<0$, $\bar{e}_{0}<\hat{e}_{G}<\tilde{e}$ and $Z^{\prime}(e)<0$ for $e>\bar{e}_{0}$.

Finally, note that $\partial \bar{e}_{0} / \partial \theta=c^{\prime}\left(\bar{e}_{0}\right) /\left[-b^{\prime \prime}\left(\bar{e}_{0}\right)+(1-\theta) c^{\prime \prime}\left(\bar{e}_{0}\right)\right]<0$, which, together with $c^{\prime \prime}<0$, implies that $c^{\prime}\left[\bar{e}_{0}(\theta)\right]$ is increasing in $\theta$. Thus $c^{\prime}\left(\bar{e}_{0}\right)-1>0$ is more likely to occur when $\theta$ is high. When $c^{\prime}\left(\bar{e}_{0}\right)-1>0$, we have proven that $\hat{e}_{G}<\tilde{e}$, which implies $c^{\prime}\left(\hat{e}_{G}\right)<1$. Since, by differentiating (13), it is found that $\operatorname{sign}\left(\partial \hat{e}_{G} / \partial \theta\right)=\operatorname{sign}\left[c^{\prime}\left(\hat{e}_{G}\right)-2\right]$, we have that $\partial \hat{e}_{G} / \partial \theta<0$ when $c^{\prime}\left(\bar{e}_{0}\right)-1>0$. Since $Z^{\prime}(e)<0$, it follows that $Z\left(\hat{e}_{G}\right)<0$ is more likely to occur the higher the level of $\theta$.

Thus, (i) $e_{G}=\hat{e}_{G}>\tilde{e}_{G}$ if $c^{\prime}\left(\bar{e}_{0}\right)-1<0$; (ii) $e_{G}=\hat{e}_{G}<\tilde{e}_{G}$ if $c^{\prime}\left(\bar{e}_{0}\right)-1>0$ and $Z\left(\hat{e}_{G}\right)>0$; and (iii) $e_{G}=\tilde{e}_{G}>\hat{e}_{G}$ if $c^{\prime}\left(\bar{e}_{0}\right)-1>0$ and $Z\left(\hat{e}_{G}\right)<0$. Case (i) occurs when the shadow cost of public funds $\theta$ is low. As $\theta$ increases we move first to case (ii) and then to case (iii). 
Proof of Lemma 3. From $(7), W_{i}(i)=\beta^{\prime}(i)-(1+\theta)\left[\gamma^{\prime}(i)-1\right]$. From $(8), W_{i}\left(i^{*}\right)=0$, whilst, using (14),

$$
W_{i}\left(i_{P}\right)=\beta^{\prime}\left(i_{P}\right)[1-(1+\theta) \alpha]+3(1+\theta) .
$$

Since $\partial W_{i}(i) \partial i<0$, it follows that if $W_{i}\left(i_{P}\right)=\beta^{\prime}\left(i_{P}\right)[1-(1+\theta) \alpha]+3(1+\theta)>0, i_{P}<i^{*}$. Given that $\theta<1$, a sufficient condition for $W_{i}\left(i_{P}\right)$ to be positive is that $\alpha \leq 1 /(1+\theta)$. From (14), gives $\partial i_{P} / \partial \alpha>0$.

Proof of Lemma 4. From (11) and (15), $e_{G}=e_{P}$, which, given Lemma 2 implies $e_{P}>e^{*}$

\section{Proof of Proposition 1.}

This follows immediately from Lemmas 1-4.

\section{Proof of Proposition 2}

First note that for delegation of contracting to be strictly optimal for $e$, it must be the case that $e_{G}=\hat{e}_{G}>\tilde{e}_{G}$, since, from Lemmas 2 and $4, \hat{e}_{G}, \tilde{e}_{G}>e^{*}$ and $\tilde{e}_{G}=e_{P}$. Thus, we need to be in case (i) in Lemma 2 .

Second, assuming that $\alpha \leq 1 /(1+\theta)$, delegation of contracting is never optimal for $i$. To see this, we use Taylor series expansions around $i=i^{*}$. Taking into account that $W_{i}\left(i^{*}\right)=0$ and $W_{i i i}(i)=0$ (so that $W_{i i}(i) \equiv W_{i i}$ is independent of $i$ ), we have $W\left(i_{P}\right)=$ $W\left(i^{*}\right)+W_{i i}\left(i_{P}-i^{*}\right)^{2} / 2$ and $W\left(i_{G}\right)=W\left(i^{*}\right)+W_{i i}\left(i_{G}-i^{*}\right)^{2} / 2$. Also, from Lemmas 1 and $3, i_{P}<i^{*}$ and $i_{G}>i^{*}$, so that, since $W_{i i i}(i)=0$, we have $i_{P}-i^{*}=W_{i}\left(i_{P}\right) W_{i i}<0$ and $i_{G}-i^{*}=W_{i}\left(i_{G}\right) W_{i i}>0$, where $W_{i}\left(i_{G}\right)$ given by (16) and $W_{i}\left(i_{P}\right)$ given by (17). Therefore, $W\left(i_{G}\right)-W\left(i_{P}\right)=\left[W\left(i^{*}\right)+W_{i i}\left(i_{G}-i^{*}\right)^{2} / 2\right]-\left[W\left(i^{*}\right)+W_{i i}\left(i_{P}-i^{*}\right)^{2} / 2\right]=$ $W_{i i}\left\{\left[W_{i}\left(i_{G}\right) W_{i i}\right]^{2}-\left[W_{i}\left(i_{P}\right) W_{i i}\right]^{2}\right\} / 2=W_{i i}^{3}\left[W_{i}\left(i_{G}\right)-W_{i}\left(i_{P}\right)\right]\left[W_{i}\left(i_{G}\right)+W_{i}\left(i_{P}\right)\right]$. Since $W_{i}\left(i_{G}\right)<$ 0 and $W_{i}\left(i_{P}\right)>0$, we have $W_{i}\left(i_{G}\right)-W_{i}\left(i_{P}\right)<0$. Also, from (16) and $(17), W\left(i_{G}\right)+W\left(i_{P}\right)=$ $\beta^{\prime}\left(i_{P}\right)[1-(1+\theta) \alpha]+2+4 \theta>0$. Hence, $W\left(i_{G}\right)-W\left(i_{P}\right)>0$.

\section{Proof of Lemma 5}

Consider investment $i$. Let $\mu$ be the fraction of $s_{P S}$ borne by $P$. Then, instead of (14), we obtain $\frac{1}{2}\left[\frac{\alpha}{\mu} \beta^{\prime}\left(i_{P}\right)-\gamma^{\prime}\left(i_{P}\right)\right]=1$. Given that $W_{i}(i)=\beta^{\prime}(i)-(1+\theta)\left[\gamma^{\prime}(i)-1\right]$, substitution 
from (14) yields $W_{i}\left(i_{P}\right)=\beta^{\prime}\left(i_{P}\right)\left[1-(1+\theta) \frac{\alpha}{\mu}\right]+3(1+\theta)$. Hence, $W_{i}\left(i_{P}\right)=0$ if $\mu=$ $\alpha \beta^{\prime}\left(i_{P}\right)(1+\theta) /\left[\beta^{\prime}\left(i_{P}\right)+3(1+\theta)\right] \equiv \bar{\mu}$. If $\alpha \leq 1 /(1+\theta), \bar{\mu}<1$.

For investment $e$, the existence of the variable budget has no effect on the argument in Section 2: $S$ implements the investment unilaterally, without negotiation. 


\section{References}

[1] Bennett, John, and Iossa, Elisabetta (2004), 'Building and managing facilities for the provision of public services,' mimeo, Brunel University.

[2] Besley, Timothy, and Ghatak, Maitreesh (2001), 'Government versus private ownership of public goods,' Quarterly Journal of Economics, 116, 1343-72.

[3] Bester, Helmut, and Sákovits, József (2001), 'Delegated bargaining and renegotiation,' Journal of Economic Behavior and Organization, 45, 459-473.

[4] Bös, Dieter, and De Fraja, Gianni (2002), 'Quality and outside capacity in the provision of health services.' Journal of Public Economics, 84, 199-218.

[5] Department of Health/Partnerships UK (2001), Public-Private Partnerships in the NHS: Modernising Primary Care in the NHS - NHS Local Improvement Finance Trust (NHS LIFT), Prospectus. Department of Health/Partnerships UK, London.

[6] Drazen, Allen (2000), Political Economy in Macroeconomics. Princeton University Press, Princeton NJ.

[7] Fershtman,Chaim, Judd, Kenneth L., and Kalai, Ehud (1991), 'Observable contracts: strategic delegation and cooperation,' International Economic Review, 32, 551-559.

[8] Grout, Paul, and Stevens, Margaret (2003), 'The assessment: financing and managing public services,' Oxford Review of Economic Policy, 19, 215-234.

[9] Harris, Clive (2003), 'Private participation in infrastructure in developing countries: trends, impacts, and policy lessons,' World Bank Working Paper No. 5, April.

[10] Hart, Oliver (2003). 'Incomplete contracts and public ownership: remarks and an application to public-private partnerships,' Economic Journal, 119, C69-C76. 
[11] Hart, Oliver, Shleifer, Andrei, and Vishny, Robert W. (1997), 'The proper scope of government: theory and an application to prisons,' Quarterly Journal of Economics, $112,1119-58$.

[12] HM Treasury (1998), Partnerships for Prosperity: The Private Finance Initiative. Treasury Taskforce, Private Finance: HM Treasury, London.

[13] Institute of Public Policy Research (IPPR) (2001), Building Better Partnerships, IPPR, London.

[14] Partnerships for Schools (PfS) (2004), Building Schools for the Future: the Local Education Partnership (LEP) Model, London.

[15] Rosenau, Pauline Vaillancourt, ed. (2000). Public-Private Policy Partnerships, MIT Press, Cambridge Mass. and London.

[16] Schelling, Thomas C. (1956), 'An Essay on Bargaining,' American Economic Review, 46, 281-306.

[17] Schelling, Thomas C. (1960), Strategy of Conflict, New York: Oxford University Press.

[18] Schmitz, Patrick W. (2000). 'Partial privatization and incomplete contracts: the proper scope of government reconsidered,' FinanzArchiv, 57, 394-411. 